\title{
Recent seismic activity in the Miyakejima and Niijima-Kozushima region, Japan - the largest earthquake swarm ever recorded-
}

\author{
Japan Meteorological Agency \\ Otemachi 1-3-4, Tokyo 100-0004, Japan
}

(Received September 1, 2000; Revised September 6, 2000; Accepted September 7, 2000)

\begin{abstract}
Seismic activity suddenly started on June 26, 2000 beneath Miyakejima, a small volcanic island located on the Izu-Bonin island arc. Then a series of swarm activity migrated toward the northwest to adjacent volcanic islands, Kozushima and Niijima, with intermittent quiet periods and spatial shifts of active areas. During the period from June 26 to the end of August, numerous earthquakes occurred, including five earthquakes of magnitude $\geq 6.0$. Here we present the outline of the swarm activity, in particular its spatio-temporal characteristics.
\end{abstract}

\section{Introduction}

Small earthquakes began to occur beneath a small volcanic island, called Miyakejima, located about $200 \mathrm{~km}$ south of Tokyo, Japan. At first we regarded this activity as related to volcanic activity, but eventually the activity migrated, first to the west and then to the northwest, as shown in Figs. 1(a) and (b). As indicated by arrows in Fig. 1(b), volcanic eruptions occurred during the swarm activity. This strongly suggests a relation between the swarm activity and the eruption, but so far no clear image has been firmly established and hence in this article we will not discuss on this matter.

Although, the activity still persists at the stage of August 25, 2000, and no one knows for sure when the activity will come to an end, we believe that a brief summary of the seismic activity by August 25 will be useful for seismologists over the world. In this article, we present a brief summary of the activity, without detailed arguments and interpretations. It should be noted that the date and the time referred to in this article are all based on the local time (JST).

\section{Outline of Seismic Swarm Activity}

Figure 1 shows the outline of seismic activity during the period from June 26 to August 26. As shown in Figs. 1(a) and (b), numerous earthquakes occurred during this period. Among them, large earthquakes are events of M6.4 on July 1, M6.1 on July 9, M6.3 on July 15, M6.4 on July 30, and M6.0 on August 18 (see Figs. 1(a) and (c)); their focal mechanisms are shown in Fig. 1(e). The spatio-temporal pattern is shown in Fig. 1(b), in which we can see some burst activities. Fig. 1(c) shows the magnitude-time plot for the two months. The number of earthquakes of $M \geq 5.0$ is about 50 , and for $M \geq 4.0$ the number exceeds 500. Figure 1(d) shows the daily numbers of earthquakes of magnitude $\geq 3.5$. Some burst activities are also well recognized in this figure.

Copy right (C) The Society of Geomagnetism and Earth, Planetary and Space Sciences (SGEPSS); The Seismological Society of Japan; The Volcanological Society of Japan; The Geodetic Society of Japan; The Japanese Society for Planetary Sciences.

\section{Migration of Swarm Activity}

As can be seen in Fig. 1(b), the swarm activity migrated from time to time. In this section we examine such characteristics in more detail. We divided the period from June 26 to August 17 into 5 phases and show the distribution of epicenters for each phase.

\section{(1) Phase I: June 26-July 1}

Figure 2(a) shows the distributions of epicenters for eight periods as indicated in each figure. We can see that a volcanic earthquake swarm started after 6 pm on June 26 in the western flank of the Miyakejima Volcano. Then the activity started to shift to the west. Next day, earthquakes tended to occur off the west coast of the island and then the activity migrated toward the northwest. During this phase, the size of earthquake seemed to increase with time. Also earthquakes tended to occur in clusters.

\section{(2) Phase II: July 1-July 9}

Figure 2(b) shows the distributions of epicenters for seven periods. A large earthquake occurred on July 1 off the east coast of Kozushima, but the aftershock activity for this earthquake soon diminished. After the occurrence of this earthquake with weak aftershock activity, swarm activity continued in the area between Kozushima and Miyakejima. In the meantime, volcanic earthquakes resumed to occur on July 4 beneath the summit of Mt. Oyama on Miyakejima, followed by eruption and collapse of the summit on July 8 . As a result of this volcanic activity, a caldela of about $1 \mathrm{~km}$ in diameter was formed on the summit.

\section{(3) Phase III: July 9-July 26}

Figure 2(c) shows the distributions of epicenters for nine periods. This phase is characterized by sporadic burst-type activities.

\section{(4) Phase IV: July 26-July 31}

Figure 2(d) shows the distributions of epicenters for four periods. During this phase, seismic activity was rather quiet except for a burst-like one in the morning of July 29.

\section{(5) Phase V: August 1-August 17}

Figure 2(e) shows the distributions of epicenters for five periods. Seismic activity resumed in the beginning of August in the area off the eastern coast of Kozushima, and then seemed to have migrated toward the southeast. 
(a)

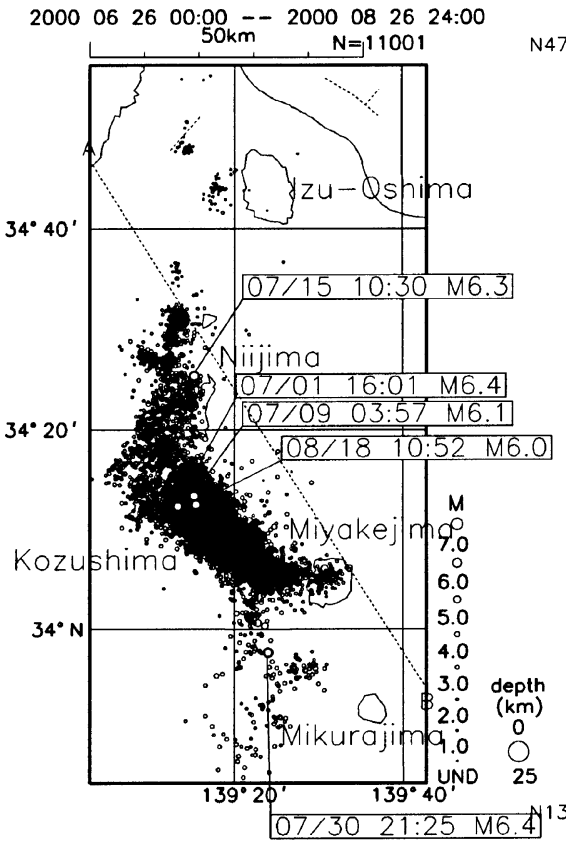

(c) (b)

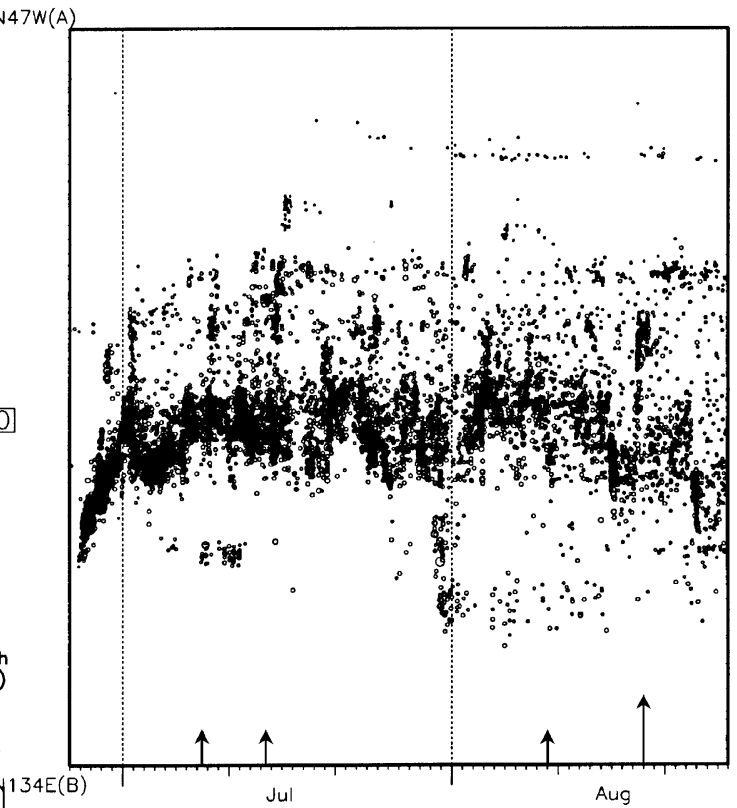

(d)
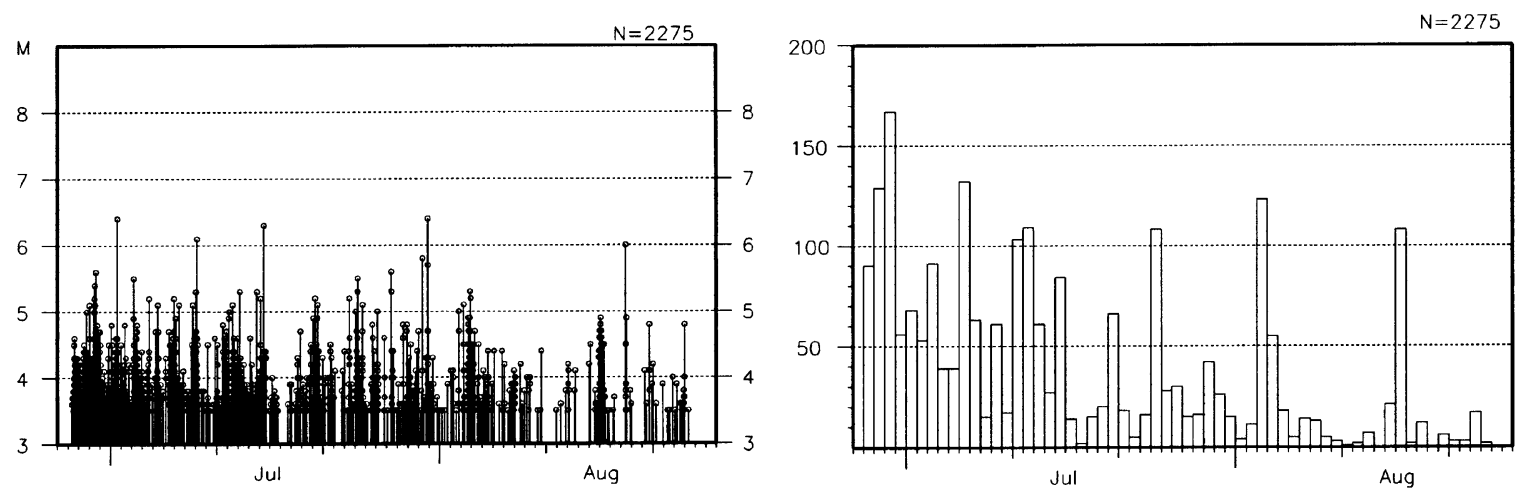

(e)

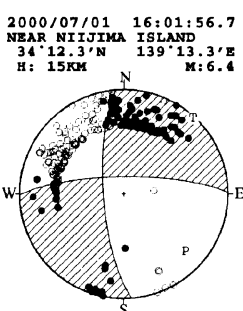

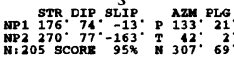
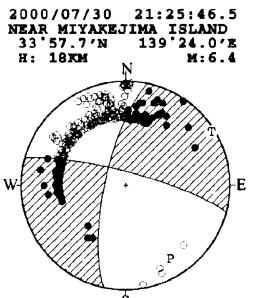

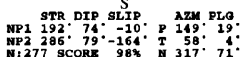

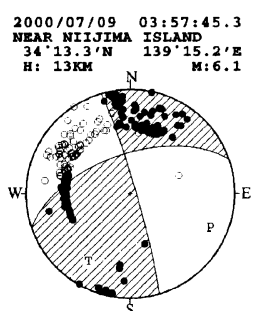

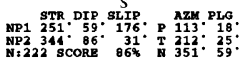

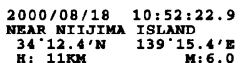

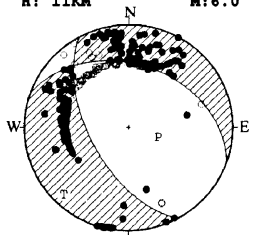

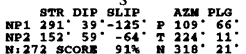

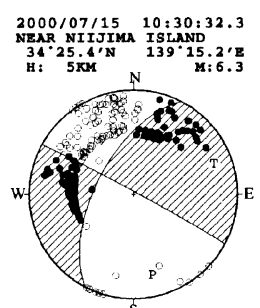

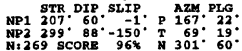

Fig. 1. Seismic activity during the period from June 26 to August 26. (a) Distribution of epicenters of the earthquakes of magnitude $\geq 6.0$. Locations of three islands, Miyakejima, Kozushima and Niijima, are also shown. (b) Distribution of epicenters projected on the A-B line, shown in (a), versus time. Arrows indicate volcanic eruptions on Miyakejima; a long one corresponds to a major event. (c) Magnitude-time plot for earthquakes of magnitude $\geq 3.5$. (d) Daily numbers of earthquakes of magnitude $\geq 3.5$. (e) Focal mechanisms of earthquakes of magnitude $\geq 6.0$. 

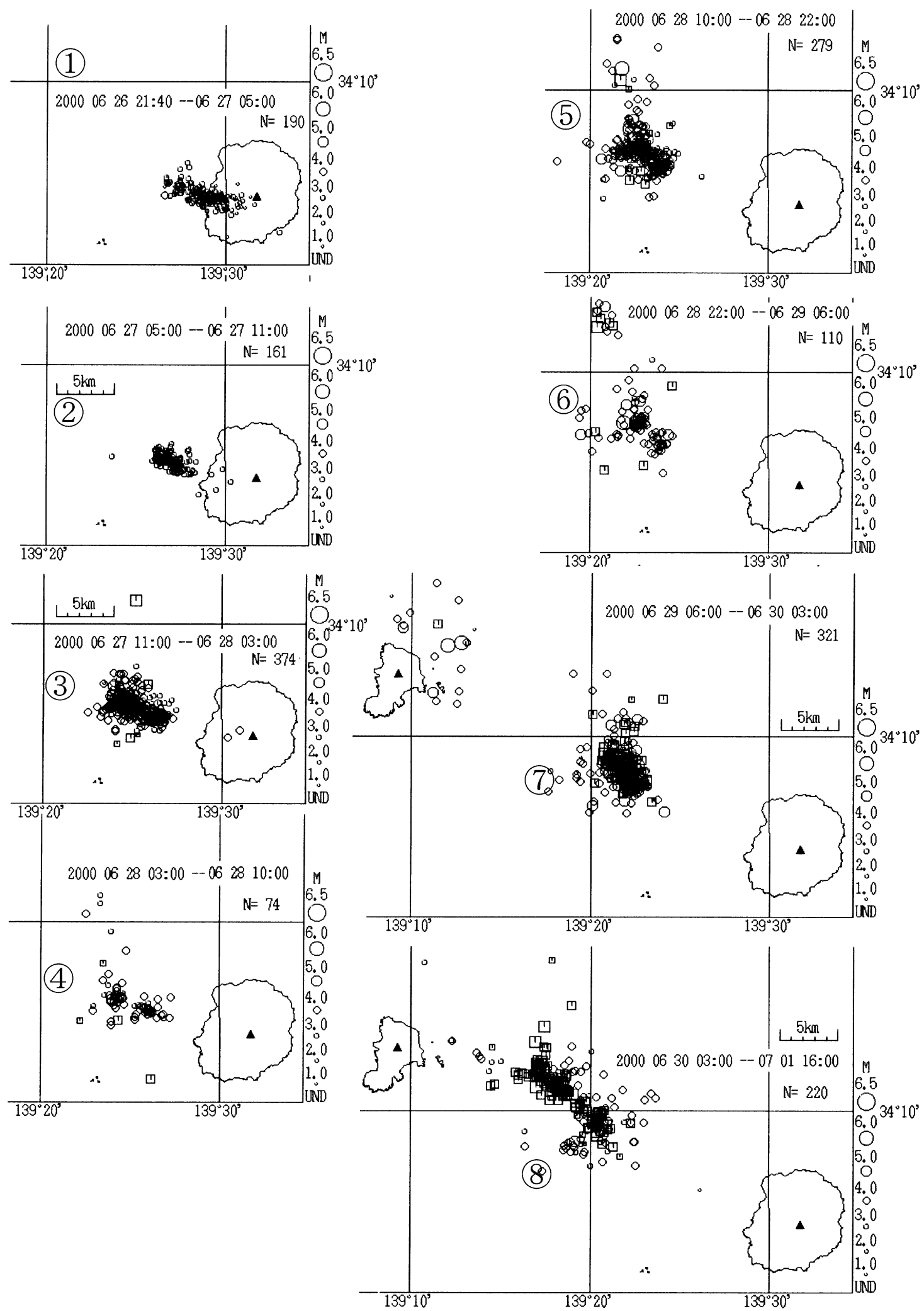

Fig. 2(a). Distributions of epicenters for Phase I (June 26-July 1). 

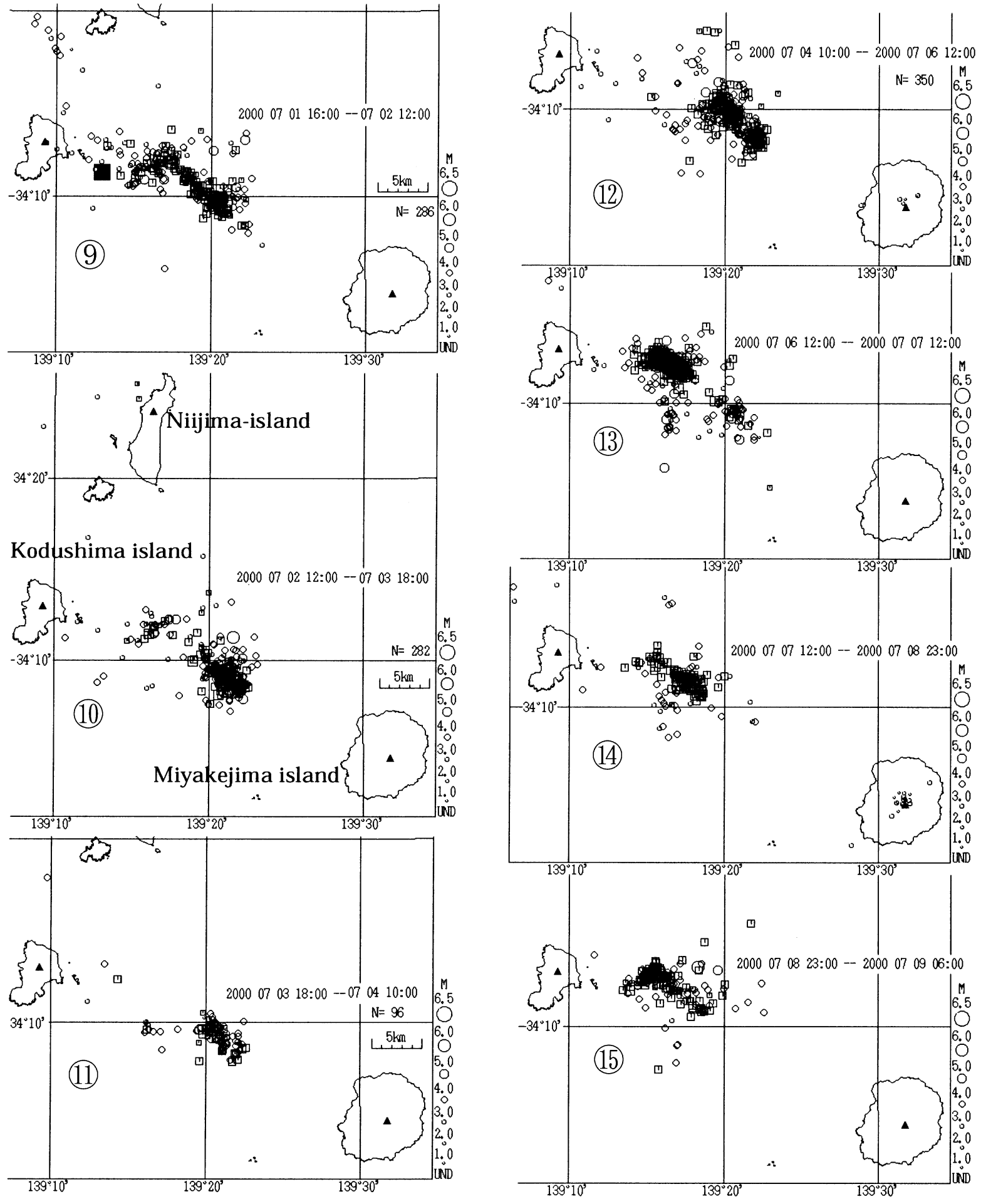

Fig. 2(b). Distributions of epicenters for Phase II (July 1-July 9). 


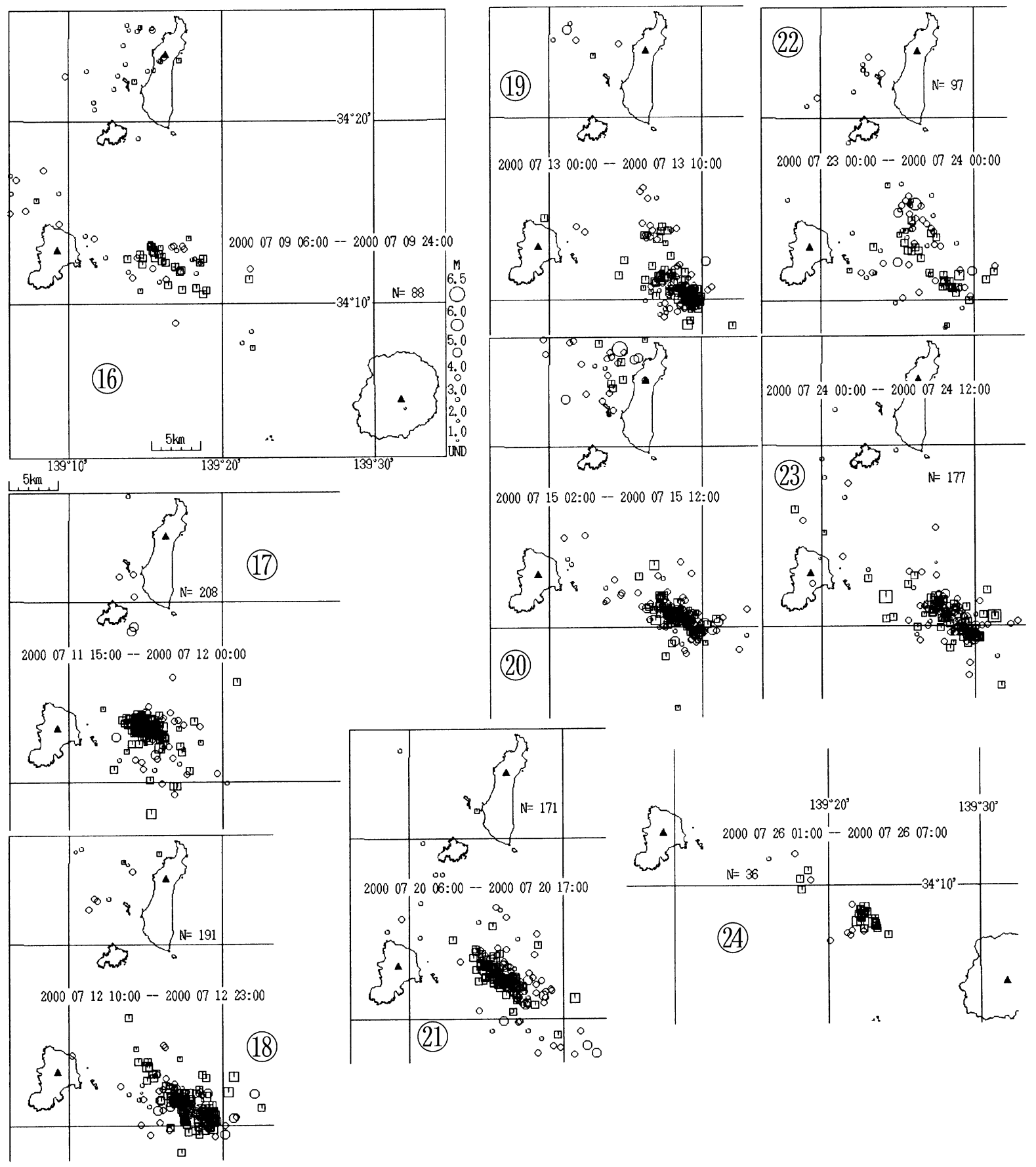

Fig. 2(c). Distributions of epicenters for Phase III (July 9-July 26). 

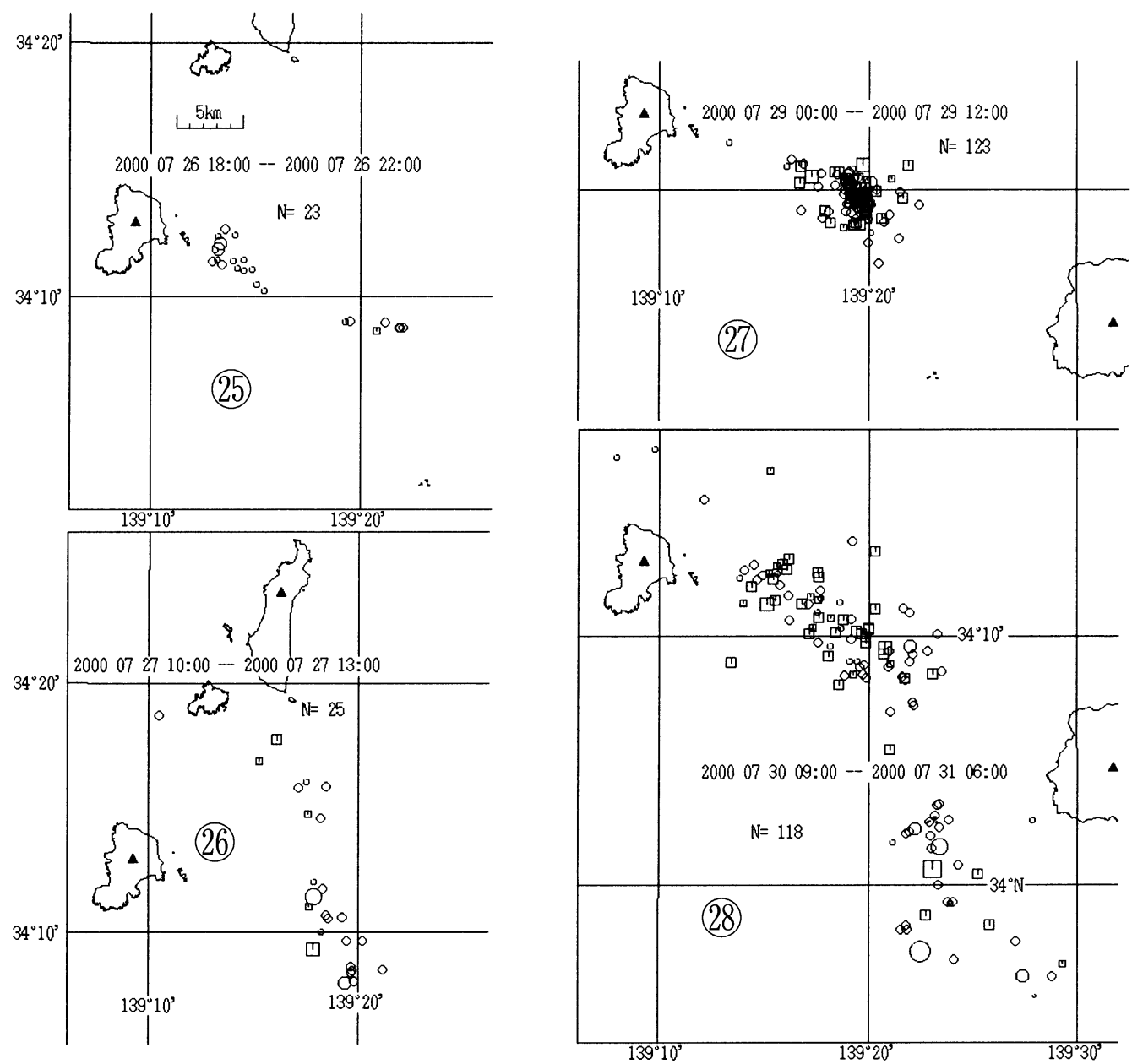

Fig. 2(d). Distributions of epicenters for Phase IV (July 26-July 31). 

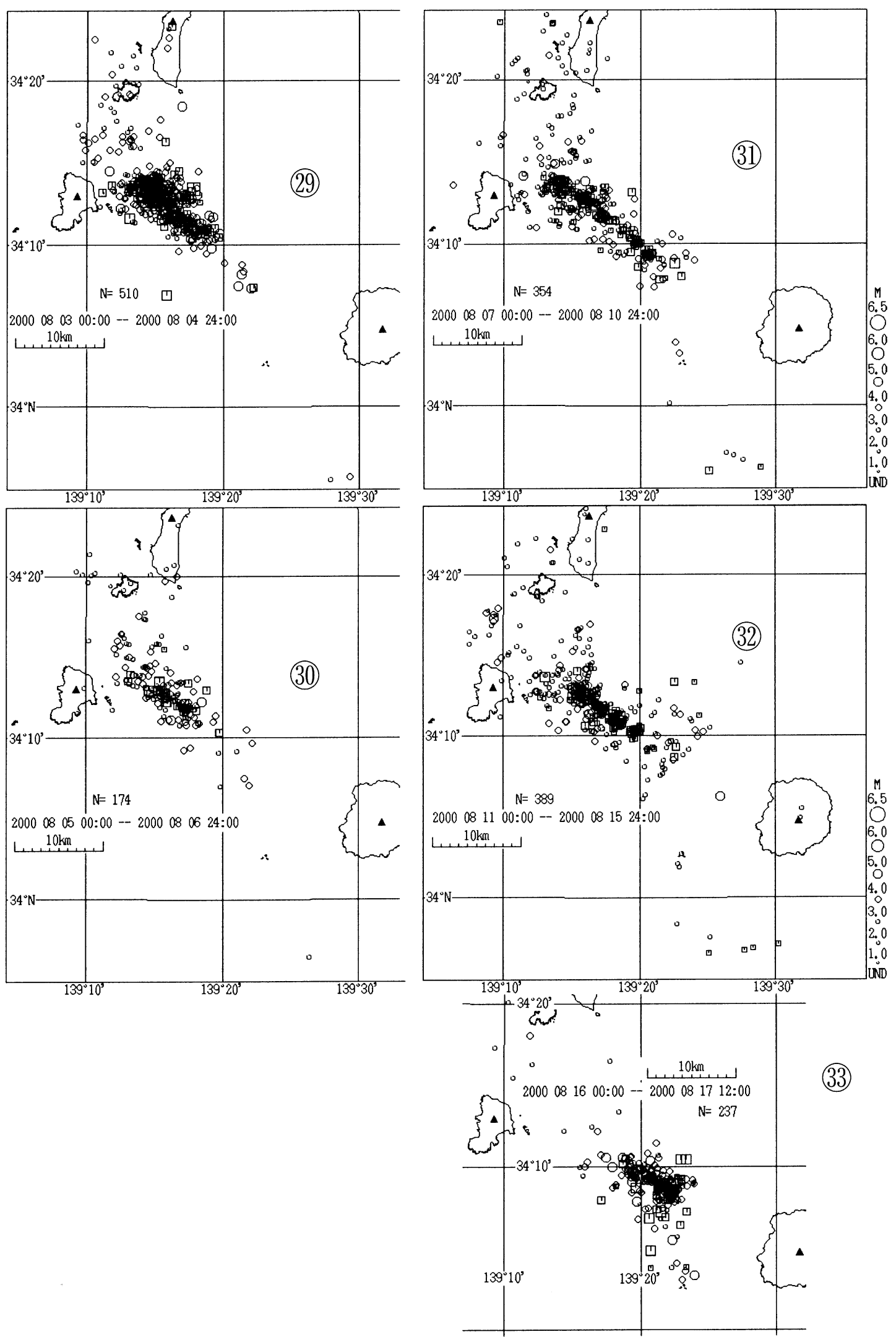

Fig. 2(e). Distributions of epicenters for Phase V (August 1-August 17). 
Seismic activity tends to decrease after August 17, but the largest eruption on Miyakejima occurred on August 18. Hydro-magmatic explosion generated a thick ash-laden plume to a height of more than $8 \mathrm{~km}$; according to the weather-radar observation, it went up to a height of $14 \mathrm{~km}$. Volcanic ejecta and thick ash covered the island, resulting in the eventual evacuation of the residents from the island.

\section{Concluding Remark}

The purpose of this article was to present the outline and some characteristics of the ongoing earthquake swarm activ- ity in the Miyakejima and Niijima-Kozushima region. We hope this article will be useful in that the outline of the ongoing activity is made open to many scientists over the world. More detailed descriptions possibly with some physical interpretations will be attempted later.

Acknowledgments. We thank Masayuki Kikuchi and Kiyoshi Yomogida for their valuable comments on the original manuscript.

Correspondence should be addressed to N. Hamada (e-mail: nhamada@, met.kishou.go.jp). 